\title{
Gold micro- and nano-particles for surface enhanced vibrational spectroscopy of pyridostigmine bromide
}

Dolgov, Leonid; Fesenko, Olena; Kavelin, Vladyslav; Budnyk, Oksana; Estrela-Llopis, Victorio; Chevychalova, Alona; Repän, Taavi; Kondratiev, Vladimir I.; Mamykin, Sergii

Published in:

Vibrational Spectroscopy

Link to article, DOI:

10.1016/j.vibspec.2016.11.005

Publication date:

2017

Document Version

Peer reviewed version

Link back to DTU Orbit

Citation (APA):

Dolgov, L., Fesenko, O., Kavelin, V., Budnyk, O., Estrela-Llopis, V., Chevychalova, A., Repän, T., Kondratiev, V. I., \& Mamykin, S. (2017). Gold micro- and nano-particles for surface enhanced vibrational spectroscopy of pyridostigmine bromide. Vibrational Spectroscopy, 88, 71-76. https://doi.org/10.1016/j.vibspec.2016.11.005

\section{General rights}

Copyright and moral rights for the publications made accessible in the public portal are retained by the authors and/or other copyright owners and it is a condition of accessing publications that users recognise and abide by the legal requirements associated with these rights.

- Users may download and print one copy of any publication from the public portal for the purpose of private study or research.

- You may not further distribute the material or use it for any profit-making activity or commercial gain

- You may freely distribute the URL identifying the publication in the public portal 


\title{
Gold micro- and nano-particles for surface enhanced vibrational spectroscopy of pyridostigmine bromide
}

Leonid Dolgov *1,2, Olena Fesenko ${ }^{3}$, Vladyslav Kavelin ${ }^{3}$, Oksana Budnyk ${ }^{3}$, Victorio Estrela-Llopis ${ }^{4}$, Alona Chevychalova ${ }^{4}$, Taavi Repän ${ }^{1,5}$, Vladimir I. Kondratiev ${ }^{1}$, Sergii Mamykin ${ }^{6}$

*Corresponding author: leonid.dolgov@ut.ee

${ }^{1}$ Institute of Physics, University of Tartu, W. Ostwald st. 1, Tartu 50411, Estonia

${ }^{2}$ School of Chemistry and Chemical Engineering, Sun Yat-Sen University, No. 135 Xingang Xi Road, Haizhu District, Guangzhou, Guangdong 510275, PR China

${ }^{3}$ Institute of Physics, NAS of the Ukraine, Prospect Nauki 46, Kyiv 03680, Ukraine

${ }^{4}$ F. D. Ovcharenko Institute of Biocolloidal Chemistry, Acad. Vernadskoho Blvd. 42, Kyiv 03142, Ukraine

${ }^{5}$ DTU Fotonik, Technical University of Denmark, Orsteds pl. 343, 2800 Kongens Lyngby, Denmark

${ }^{6}$ V. Lashkaryov Institute of Semiconductor Physics, NAS of Ukraine, Prospect Nauki 41, Kyiv 03028, Ukraine

\begin{abstract}
Triangular gold microprisms and spherical silica nanoparticles with attached gold nano-islands were examined as an active nanostructures for the surface enhanced Raman and infrared spectroscopy. These particles were probed for the detection of pyridostigmine bromide as a safe analog of military compound sarin. Raman and infrared spectral bands of the pyridostigmine bromide were measured. Detailed correlation of obtained spectral bands with specific vibrations in pyridostigmine bromide was done. Silica nanoparticles with attached gold nano-islands showed more essential enhancement of the Raman signal than gold microcrystals. The reasons of such behaviour are discussed.
\end{abstract}

Keywords: SERS, SEIRA, gilded nanoparticles, pyridostigmine bromide.

\section{Introduction}

Nanosized particles of noble metals can work as an optical antennas enhancing spectral signal from the analyte molecules adsorbed on them [1-5]. This effect is actively used in Surface Enhanced Raman Scattering (SERS) [6-10] and Surface Enhanced InfraRed Absorption (SEIRA) spectroscopies [5, 1114]. Electromagnetic and chemical mechanisms of Raman enhancement are usually mentioned [1517]. Electromagnetic mechanism is connected with resonant coupling of exciting or scattered light with oscillations of surface electron plasma localized in the noble metal nanoparticles [17]. As a necessary condition for this effect the frequency of the exciting light should be in resonance with plasmon oscillations in the noble metal nanoparticles. Experimentally it is fulfilled when the wavelength of the exciting light is spectrally overlapped with the band of light extinction inherent to the nanoparticles. It results in the essential growth of local electric field near the particle and increase in cross section of Raman scattering or infrared light absorption.

Chemical mechanism of Raman enhancement is connected with the electron transfer from the substrate to the absorbed molecule. It becomes possible, when the exciting light resonantly transfers electron from the Fermi level of the substrate to the lowest unoccupied molecular orbital of the adsorbed analyte [18-23].

Non-invasive SERS and SEIRA spectroscopical methods for detection of minute amounts of material become more and more usable not only for the laboratory analyses, but also for the applied needs. Development of nanostructured surfaces and progress in preparation of nanoparticles turned more intent attention to the surface enhanced Raman and infrared spectroscopies. Particularly it was demonstrated that these methods are prospective for the detection of hazardous admixtures. Thus gold 
nanoparticles were used for the SERS detection of melamine in the raw milk [24]. Traces of explosive materials both deposited from dilute solutions [25] and adsorbed on the nanostructured substrates from air [26, 27] were sensed. Hakonen and colleagues [28] demonstrated maybe the only ultra-sensitive SERS study on actual chemical warfare agents present up to date. Femtomol detection of VX and Tabun were shown. Lauridsen and colleagues reported about possibility of sensing traces of cyanide in air by means of specially prepared gilded silicon nanopillars [29].

The work with hazardous compounds is complicated and requires an additional accident control measures. Therefore pyridostygmine bromide was used as model compound instead of hazardous sarin (Fig. 1). An analogy between these chemicals consists in their common ability of conjugation with cholinesterase in the human synapses. Though pyridostigmine bromide is able to substitute the dangerous sarin near the cholinesterase and by such a way it works as an antidote to sarin [30-33]. As far as we know there is lack of knowledge about the vibrational spectra of pyridostygmine bromide. We found only one reference [34] with Raman spectrum of relative neostigmine compound, which is given without assignment of bands with certain types of molecular vibrations.

Here Raman and infrared spectra of pyridostygmine bromide are measured. Spectral bands are assigned with molecular vibrations. Possibilities for surface enhanced Raman scattering are tested on two types of nanoparticles: spherical silica nanoparticles with attached gold nano-islands $\left(\mathrm{SiO}_{2}-\mathrm{Au}\right)$ and triangular prismatic microcrystals. It was revealed that $\mathrm{SiO}_{2}-\mathrm{Au}$ nanoparticles are more Raman active than prismatic microcrystals of gold.

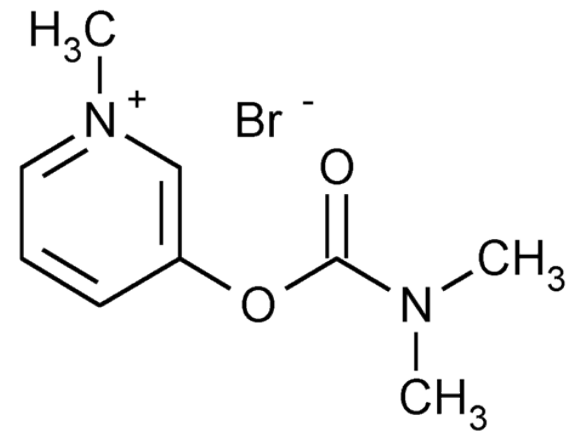

a<smiles>CC(C)OP(C)(=O)F</smiles>

b

Fig. 1. Chemical formulas of pyridostigmine bromide (a) and sarin (b).

\section{Materials and methods}

Pyridostigmine bromide powder from the company Sigma Aldrich was diluted in water in concentration $40 \mathrm{mg}$ per litre.

$\mathrm{SiO}_{2}$ nanoparticles were prepared by Stöber method [35] and functionalized by amino groups providing good covering of the silica core by the gold seeds [36]. $\mathrm{SiO}_{2}-\mathrm{Au}$ nanoparticles dispersed in water were obtained. Plasmonic light extinction by dispersion of $\mathrm{SiO}_{2}-\mathrm{Au}$ nanoparticles was confirmed by using Jasco V-570 spectrophotometer (Easton, MD, USA) [37].

Another kind of particles, gold microcrystals, were grown in water solution of chloroauric acid with polysaccharides as reducing and stabilizing agent $[38,39]$. The particles have mostly the shape of a triangular prism ranging from nanometers to 5-10 micrometers in size. As such they look prospective for the enhancement of optical signals from organic and inorganic probes. The particles were washed carefully to minimize the influence of polysaccharides.

Each from two types of prepared dispersions was dropped and dried on the glass surface. Then pyridostigmine solution was dropped on the top of particles. The referent pyridostigmine droplets were deposited also on the neat glass for the comparison.

Raman signal was measured on the Revishaw inVia microRaman setup with $633 \mathrm{~nm}$ excitation from the He-Ne laser. Spectra of infrared light absorption were recorded by means of FT-IR spectrometer VERTEX 70 with microscope Hyperion 1000 from Bruker Optic GMBH. 


\section{Results and discussion}

Droplet of pyridostigmine solution deposited on the glass substrate gives more or less homogeneous film after drying at room conditions (Fig. 2).

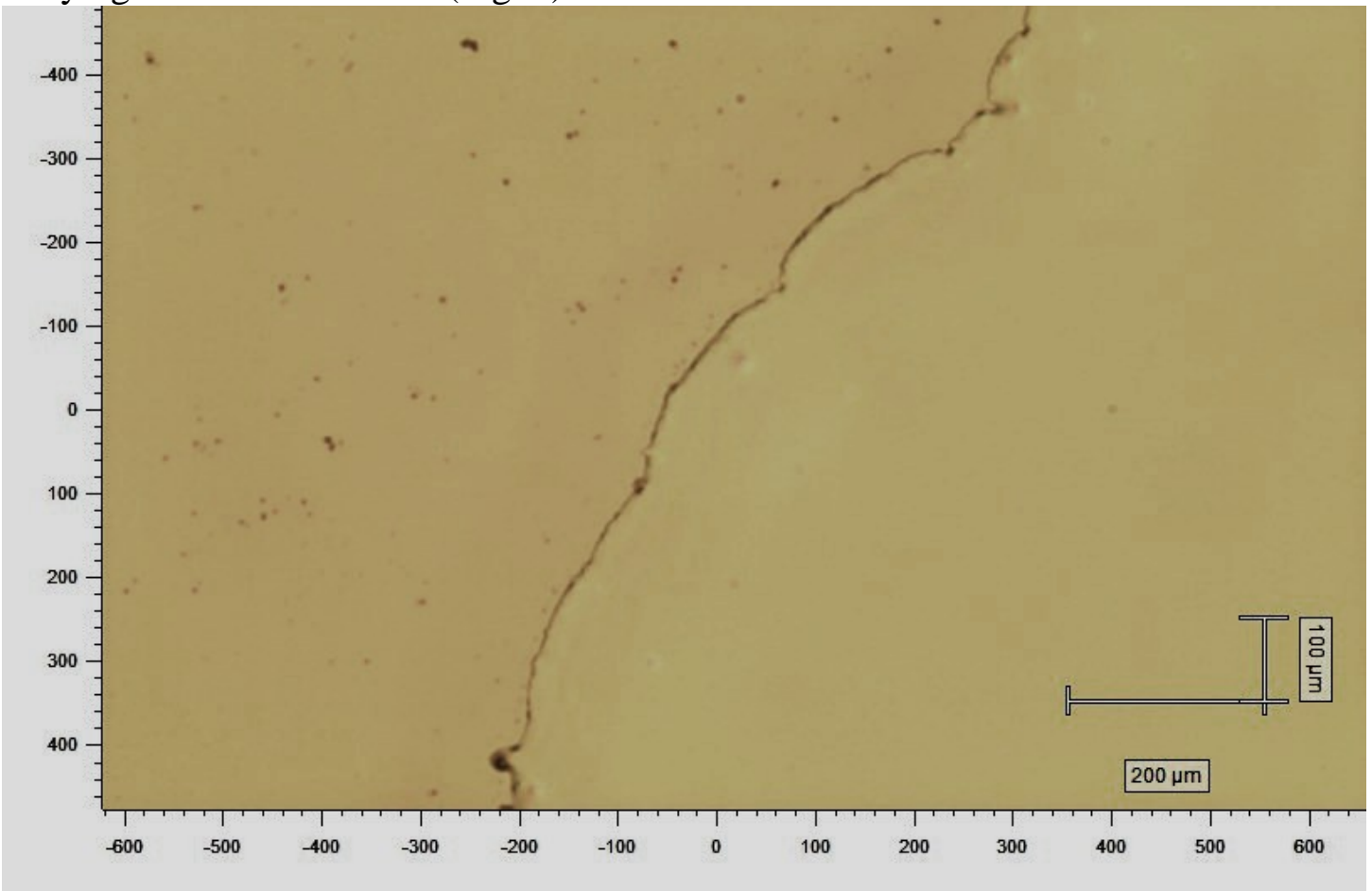

Fig. 2. Optical microscopic image of pyridostigmine bromide droplet dried on the glass surface.

Initially it was not possible to obtain a sharp focused image from the area of the immediately dried droplet. It turns us to the suggestion that material is still keeping some amount of water after initial drying. It means that fresh film is situating in a gel-like state. Probably because of this there was a strong fluorescence hindering of the useful Raman signal from the freshly prepared film.

\subsection{Raman spectra of pyridostigmine bromide}

Pyridostigmine bromide droplets deposited on the thin gold films based on the glass showed better results. More intensive laser light in combination with good thermal conductivity of gold resulted in better drying of measured film area. So at higher laser intensity Raman spectrum of material became apparent on the fluorescent background (Fig. 3, spectra 2 and 3). 


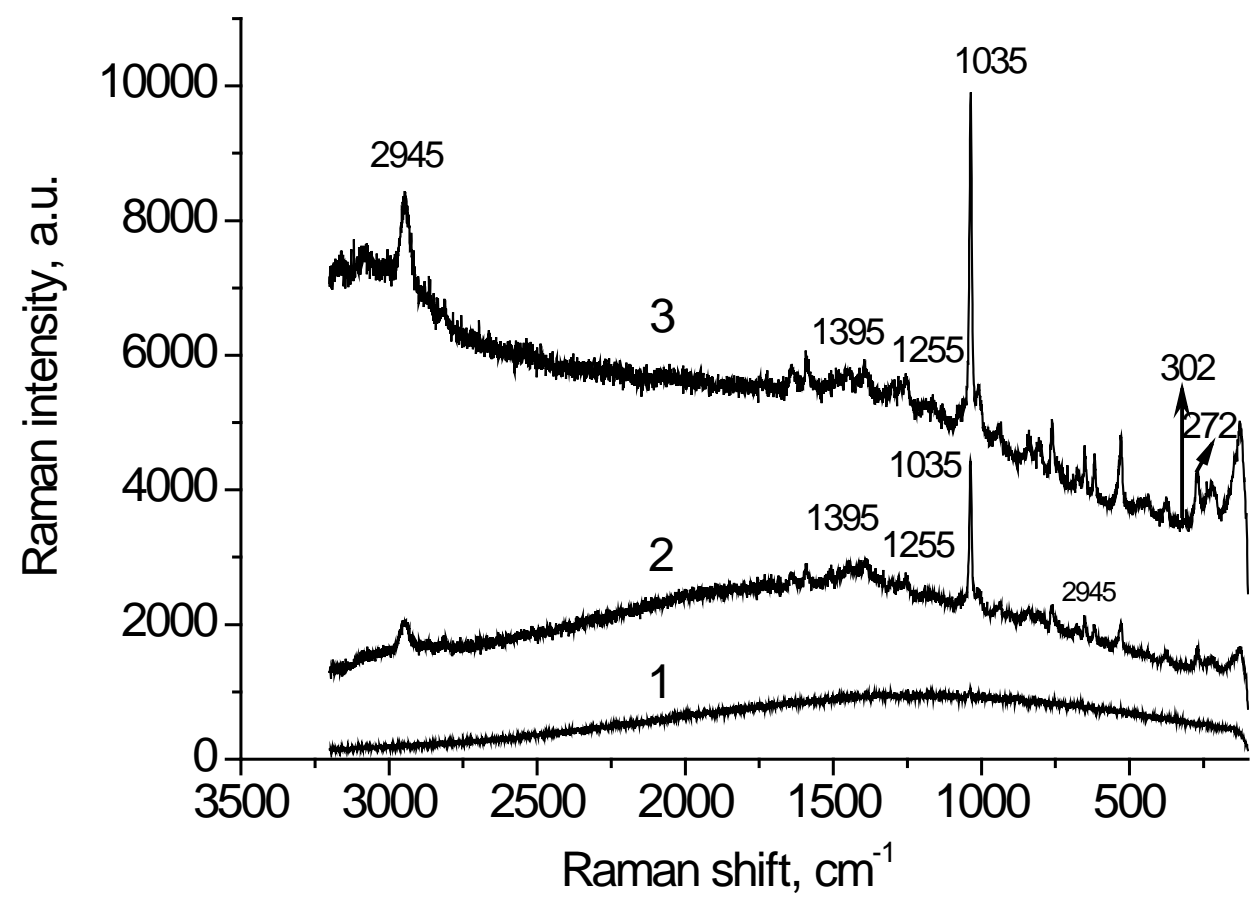

Fig. 3. Spectra from the pyridostigmine bromide film deposited on the thin gold films based on the glass and measured at different powers of incident laser light: 1) $1 \%$, 2) $50 \%$, 3) $100 \%$. Full laser power is $50 \mathrm{~mW}, \lambda_{\text {exc }}=633 \mathrm{~nm}$.

Such assignment of the most pronounced Raman bands with molecular vibrations of pyridostigmine bromide molecule can be done: the band at $2945 \mathrm{~cm}^{-1}$ is related to $\mathrm{C}-\mathrm{H}$ stretching vibrations of the methyl group and the pyridine ring; set of bands in the range $1200-1500 \mathrm{~cm}^{-1}$ are caused by skeleton vibrations of the pyridine ring; $\mathrm{C}-\mathrm{N}$ stretching vibrations of the tertiary amine can be associated with the group of bands at 1000-1200 $\mathrm{cm}^{-1}$. Small peaks at $272 \mathrm{~cm}^{-1}$ and $302 \mathrm{~cm}^{-1}$ can be assigned with pyridine and bromine constituents of a pyridostigmine bromide molecule as it is pointed in the Ref [40]. Detailed correlation of pyridostigmine bromide bands with vibrations of its molecular groups is represented in Table 1.

Table 1. Correlation of pyridostigmine bromide Raman bands with vibrations of its molecular groups.

\begin{tabular}{ll}
\hline Raman shift, $\mathrm{cm}^{-1}$ & Description \\
\hline $272 \mathrm{~cm}^{-1}$ & Pyridine constituent in pyridostigmine bromide molecule \\
$302 \mathrm{~cm}^{-1}$ & Bromine constituent in a pyridostigmine bromide molecule \\
$1000-1200 \mathrm{~cm}^{-1}$ & C-N stretching vibrations of the tertiary amine \\
$1200-1500 \mathrm{~cm}^{-1}$ & Skeleton vibrations of pyridine \\
$1734 \mathrm{~cm}^{-1}$ & C=O stretching vibrations of the ester carbonyl \\
$2945 ; 3055 \mathrm{~cm}^{-1}$ & C-H stretching vibrations of the methyl group and the
\end{tabular}




\subsection{Spectra of infrared light absorption by pyridostigmine bromide}

Droplets of pyridostigmine bromide solution were deposited either on the continuous gold film or on the traces from preliminary dropped $\mathrm{SiO}_{2}$-Au dispersions. It allowed us to estimate possible influence of substrate on the intensity of spectral signal. Features of this effect are described here and in the next section 3.3.

Droplets of pyridostigmine bromide deposited on the $\mathrm{SiO}_{2}$-Au nanoparticles demonstrate stronger infrared absorption than referent droplet on the continuous gold film (Fig. 4, spectra 1, 2). This SEIRA effect is less pronounced than SERS. The traces of dried dispersions consist of soft aggregates of $\mathrm{SiO}_{2}$ Au particles. So it looks so that light scattering by these aggregates is stronger than light absorption.

In addition it was revealed that the traces of dried $\mathrm{SiO}_{2}$-Au dispersions have own spectral signatures (Fig. 4, spectrum 3). It can be a side effect of synthesis, in which ammonia, sodium hydroxide and potassium carbonate were used. Sequential measurements of infrared absorption from: (1) $\mathrm{SiO}_{2}-\mathrm{Au}$ dispersion, (2) neat pyridostigmine bromide and (3) pyridostigmine bromide deposited on the $\mathrm{SiO}_{2}-\mathrm{Au}$ nanoparticles allowed us to separate pyridostigmine bromide bands (Fig. 4). They can be correlated with such vibrational modes: bands at 2945 and $3055 \mathrm{~cm}^{-1}$ can be caused by $\mathrm{C}-\mathrm{H}$ stretching vibrations of the methyl group and the pyridine ring; bands at $1000-1200 \mathrm{~cm}^{-1}$ are due to $\mathrm{C}-\mathrm{N}$ stretching vibrations of the tertiary amine; and bands at $1200-1500 \mathrm{~cm}^{-1}$ are connected with skeleton vibrations of the pyridine ring; $\mathrm{C}=\mathrm{O}$ stretching vibrations of the ester carbonyl can be associated with band at $1734 \mathrm{~cm}^{-1}[40,41]$.

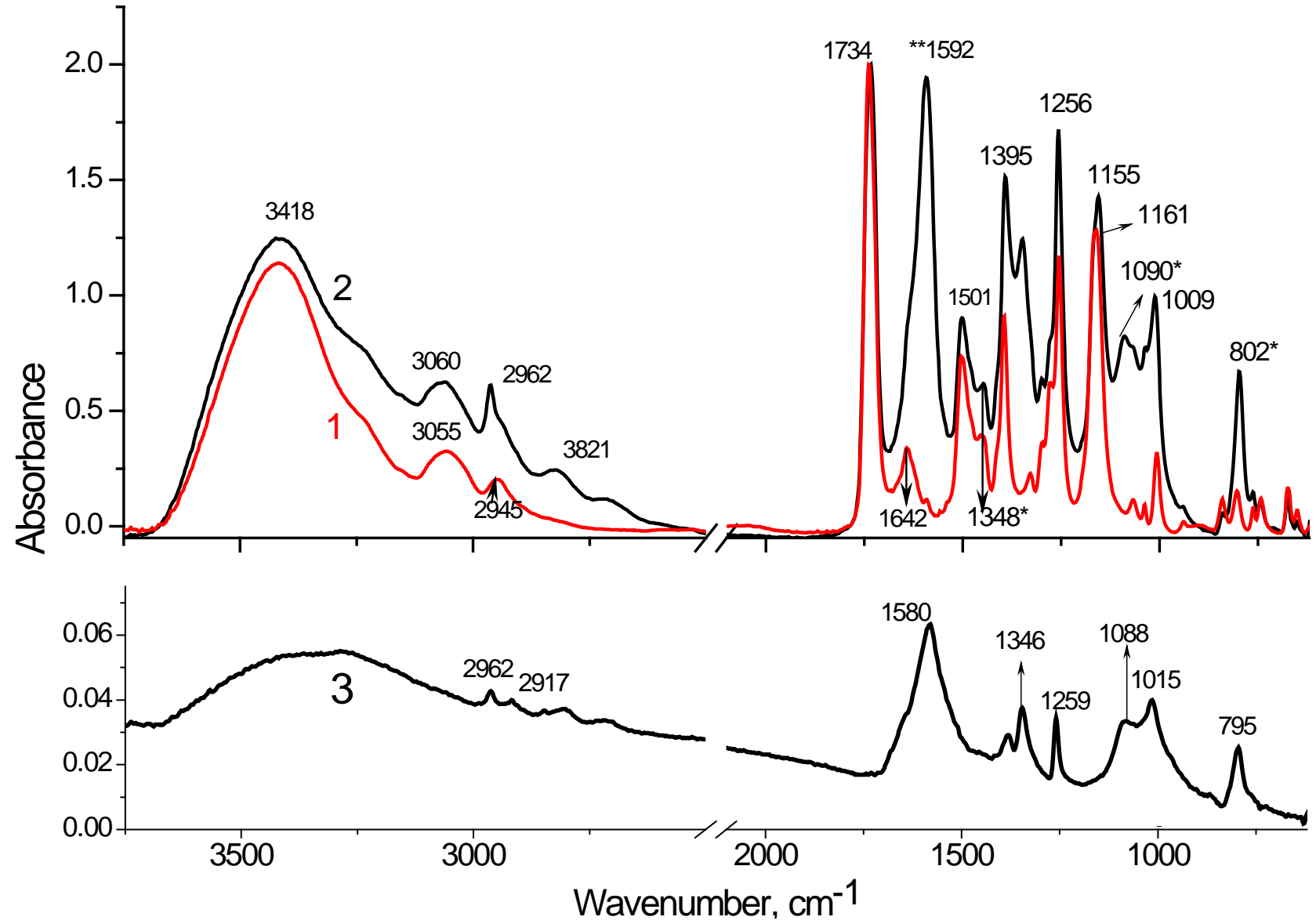

Fig. 4. Spectra of the infrared light absorption for the samples: (1) pyridostigmine bromide deposited on continuous gold film; (2) pyridostigmine bromide deposited on the $\mathrm{SiO}_{2}$-Au nanoparticles; (3) dried dispersion of $\mathrm{SiO}_{2}$-Au nanoparticles. 


\subsection{Effects of Surface Enhanced Raman Scattering revealed for pyridostigmine bromide samples}

Triangular gold microprisms and $\mathrm{SiO}_{2}$-Au nanoparticles were considered as metal nanostructures for plasmonic enhancement of Raman signal from the pyridostigmine bromide. Each type of particles is described consistently.

Microscope appearance of microprisms depends on their orientation with respect to the incident light. Microprism behaves as a mirror at normal light incidence. Therefore it looks shining under direct illumination. Side illumination leads to more intensive light scattering from the microprims' facets (Fig. 5a). It correlates with localization of light induced electric field near the prism facets calculated by means of COMSOL software package.

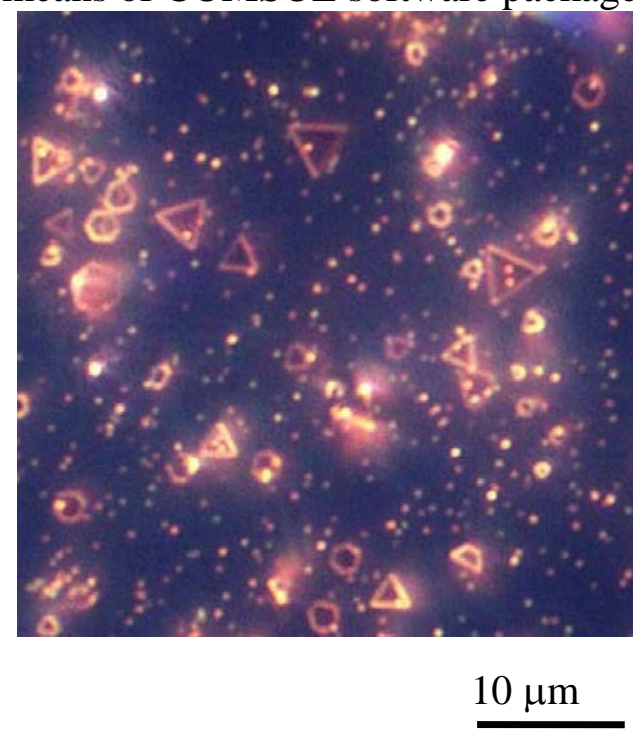

a

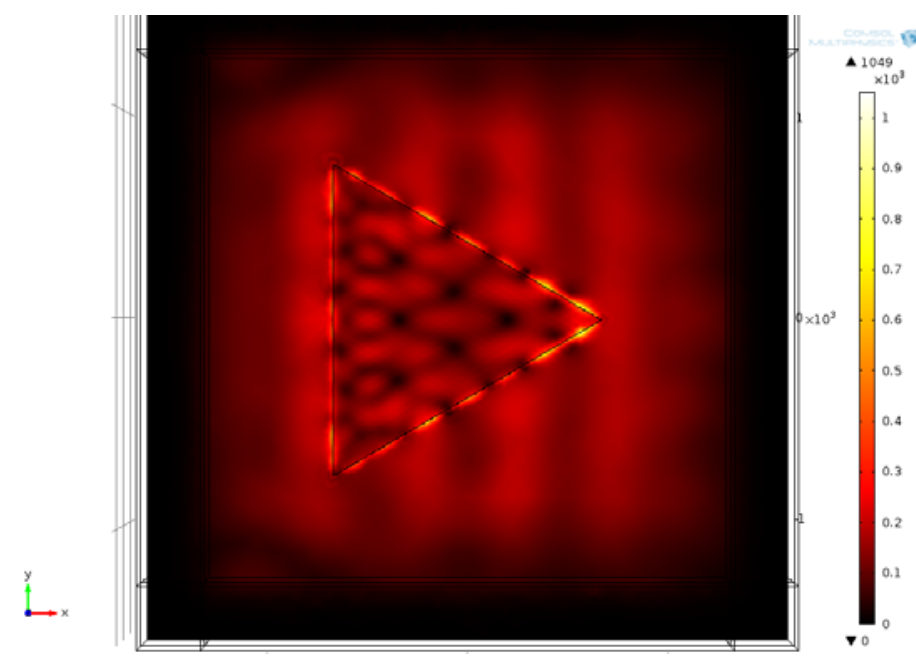

b

Fig. 5. Experimental optical microscope image of dark field light scattering from the facets of the gold microcrystals (a). Calculated distribution of light induced electric field for the gold prism with the $1.5 \mu$ m edge under normally incident light $\left(\lambda_{\text {exc }}=633 \mathrm{~nm}\right)(\mathrm{b})$.

Alteration of high and low electric field intensity occurs along the microprism's facets (Fig. 5b). It is typical for the standing wave pattern of surface plasmon polaritons. They could cause changes in Raman signal of the nearby pyridostigmine bromide. We suggested that effect could be even stronger in the spaces between the several gathered microprisms, which can form so-called hot spots for the plasmon electric field [42].

As it was mentioned above, droplets of pyridostigmine bromide solution gave no Raman signal in the absence of gold. So there is a question about the referent Raman spectrum with which SERS data can be compared. We used approach described by Hakonen and co-authors in Ref [27]. Referent Raman signal was measured from the small solid grain of pyridostigmine bromide. The amount of molecules contributing to the usual Raman signal $\mathrm{N}_{\text {Raman }}$ was estimated as $10^{10}$. The number of molecules $\mathrm{N}_{\text {SERS }}$ contributing to the SERS signal was estimated as 3.7·10 ${ }^{8}$. Enhancement factor EF was calculated as ratio of Raman intensities correlated to the number of contributed molecules: $\mathrm{EF}=\left(\mathrm{I}_{\mathrm{SERS}} / \mathrm{N}_{\mathrm{SERS}}\right) /\left(\mathrm{I}_{\text {Raman }} / \mathrm{N}_{\text {Raman }}\right)$.

Experimental Raman bands from pyridostigmine bromide contacted with gold microprisms were moderately enhanced (Fig. 6). Enhancement factor calculated for the strongest Raman peak at 1034 $\mathrm{cm}^{-1}$ is 4854 . 


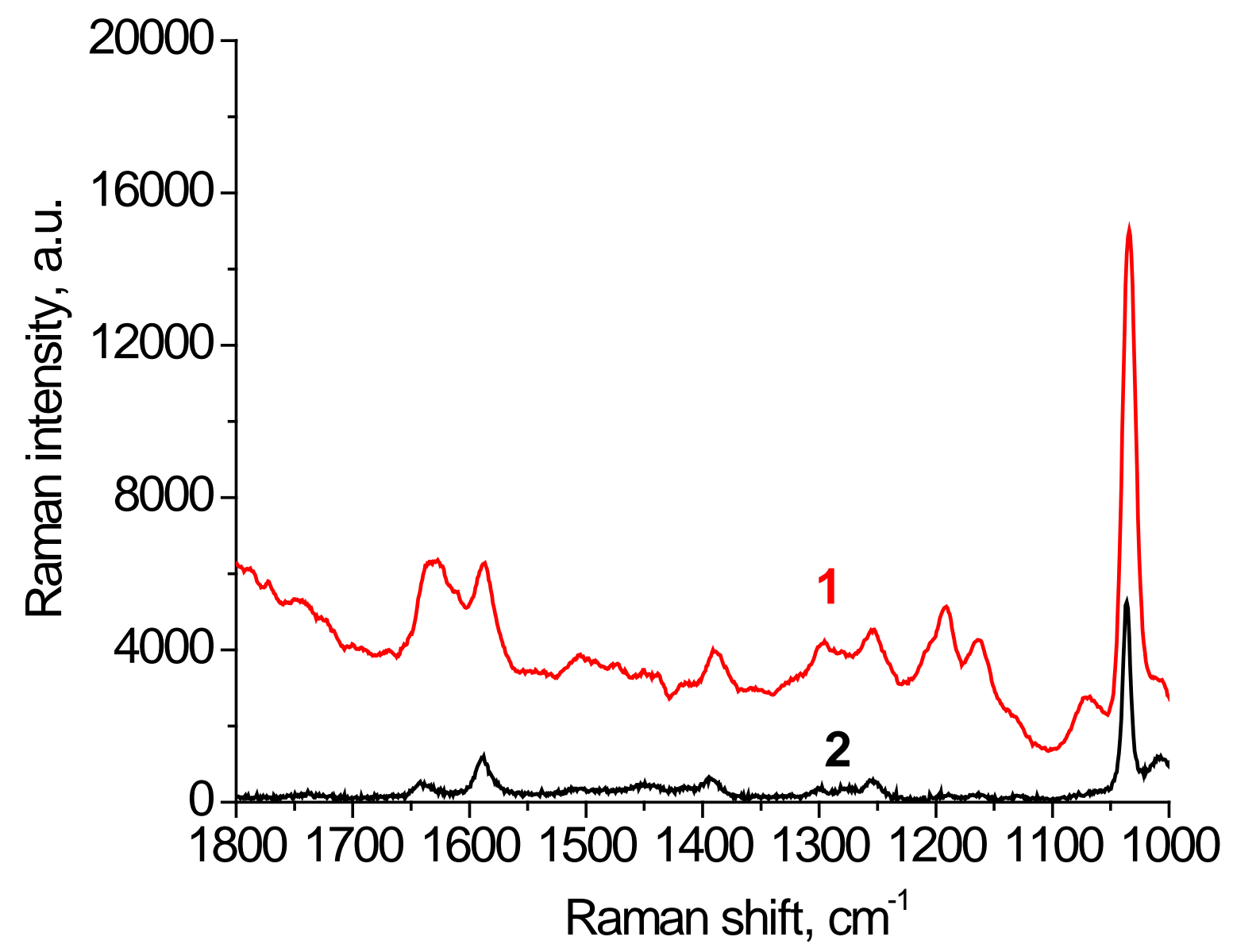

Fig. 6. Raman spectra from the pyridostigmine droplet dried on the gold microprisms (1) in comparison with referent spectrum from the grain of pyridostigmine bromide (2). Depicted intensity of spectrum (2) is 50 times higher than real one for the more convenient comparison of (1) and (2). Fluorescent background is subtracted.

Pronounced Raman enhancement of pyridostigmine bromide spectrum was obtained in case of its deposition on the top of $\mathrm{SiO}_{2}-\mathrm{Au}$ nanoparticles. Enhancement factor calculated by the same way for the $1034 \mathrm{~cm}^{-1}$ peak gives enhancement factor $E F=5 \cdot 10^{8}$. Such enhancement allows detection of nanograms of pyridostigmine bromide. 


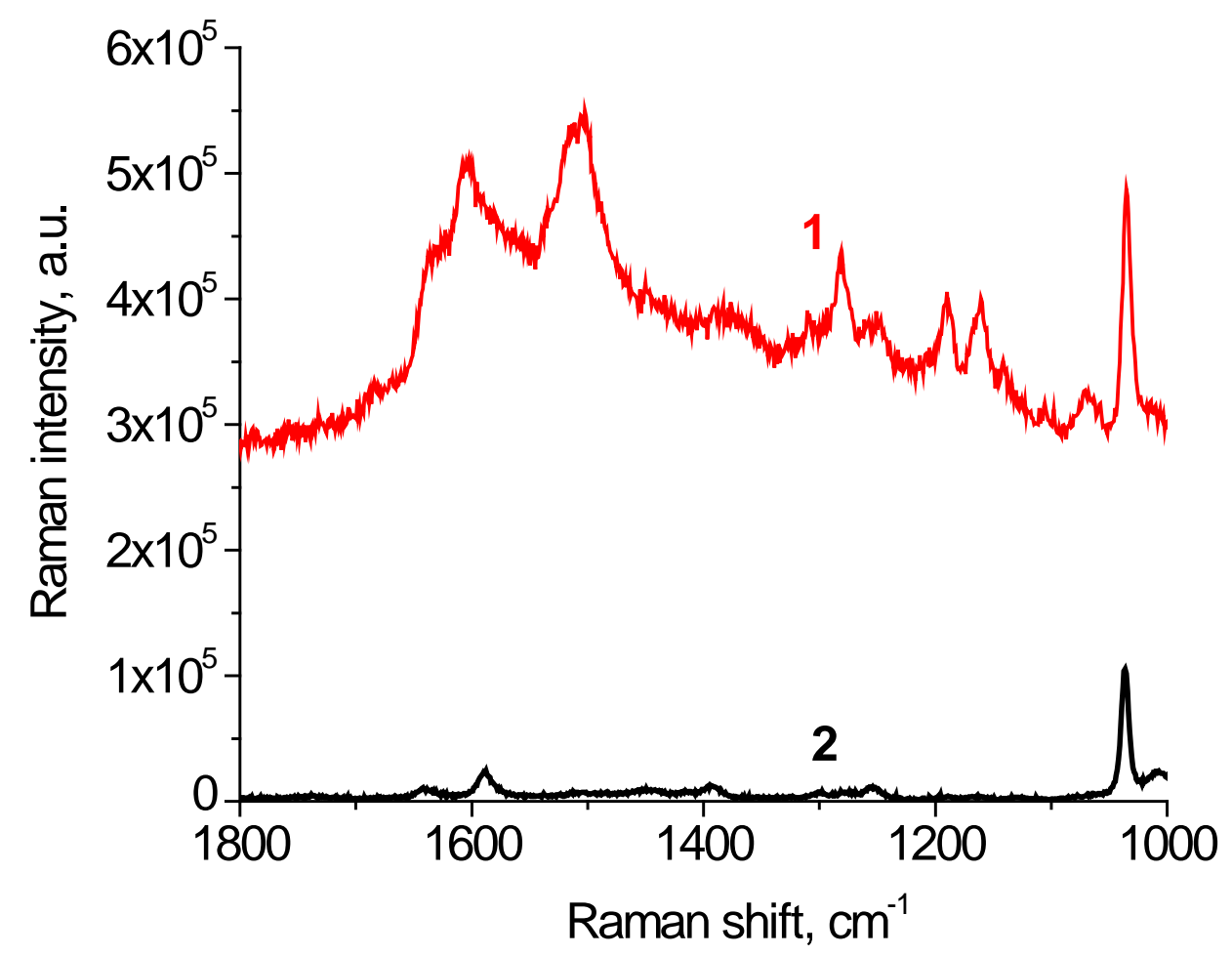

Fig. 7. Raman spectra from the pyridostigmine droplet dried on the $\mathrm{SiO}_{2}$-Au nanoparticles (1) in comparison with referent spectrum from the grain of pyridostigmine bromide (2). Depicted intensity of spectrum (2) is $10^{3}$ times higher than real one for the more convenient comparison of (1) and (2). Fluorescent background is subtracted.

Such strong Raman enhancement can be connected with specific rough surface created by the gold nanoseeds merged on the surface of silica spheres (Fig. 8) and their quite broad plasmonic resonance $[37,43]$. We suppose that rough surface of these particles can be the source of plasmonic hot spots enhancing the signal from the pyridostigmine. 


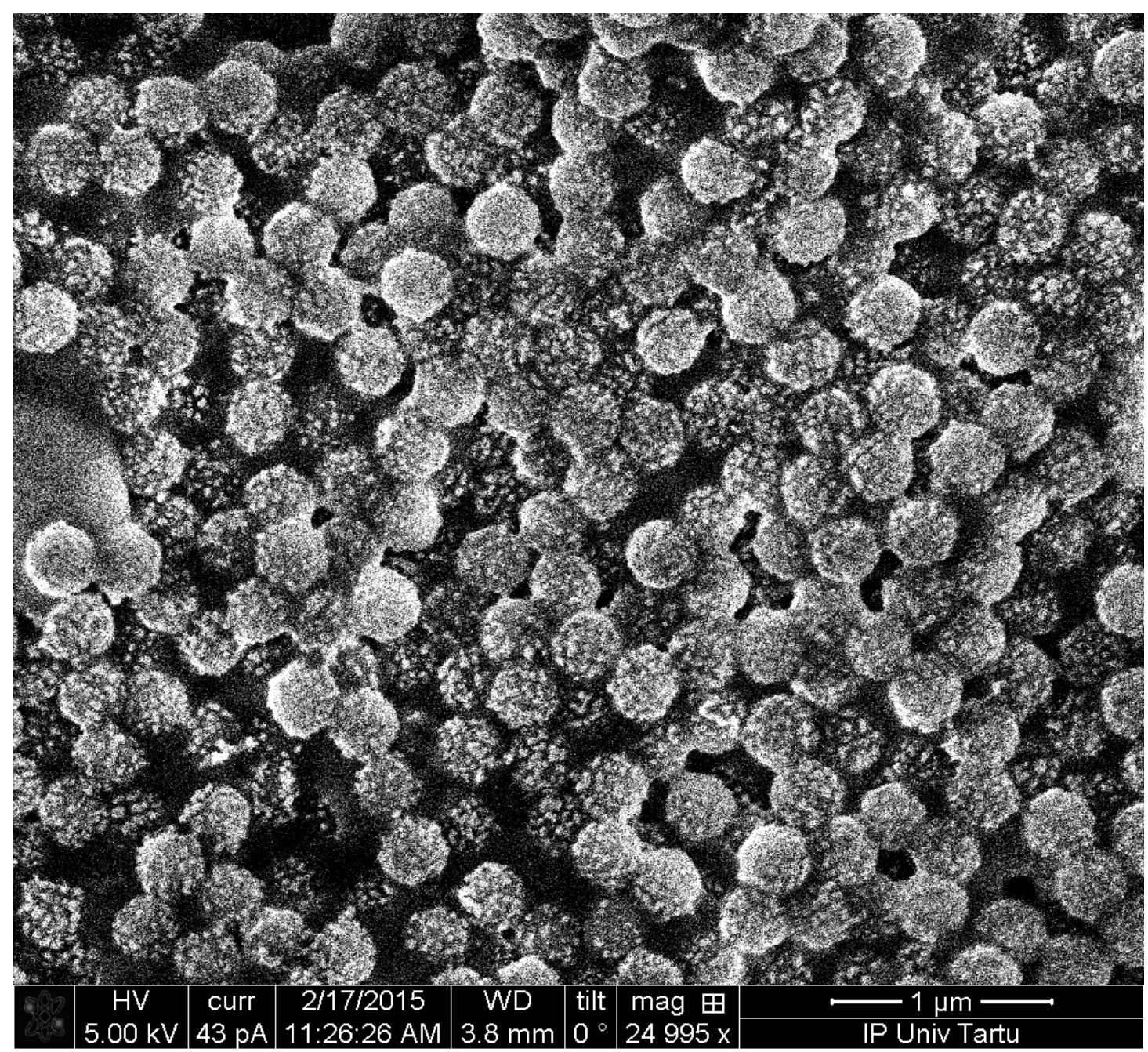

Fig. 8. Scanning electron microscopy of $\mathrm{SiO}_{2}-\mathrm{Au}$ nanoparticles.

\section{Conclusions}

Silica nanoparticles with attached gold nano-islands are used for the detection of pyridostigmine bromide, which acts as an antidote to sarin chemical agent. It is shown that these $\mathrm{SiO}_{2}-\mathrm{Au}$ nanoparticles more effectively enhance Raman and infrared signals than gold microcrystals. Particularly Raman signal from pyridostigmine bromide deposited on the $\mathrm{SiO}_{2}$-Au nanoparticles can be enhanced up to the eight orders. This enhancement can be associated with more effective excitation of plasmons localized in $\mathrm{SiO}_{2}$-Au nanoparticles. The strongest Raman and infrared spectral bands are detected in the spectral range $1000-1200 \mathrm{~cm}^{-1}$ and connected with C-N stretching vibrations of the tertiary amine in the pyridostigmine molecule.

\section{Acknowledgements}

This work was supported by NATO SPS project NUKR.SFPP984702 and partially by the Estonian Research Council (institutional project IUT34-27), Marie Curie ILSES project no. 612620. We would like to acknowledge Prof. Alain Geloen from the INSA de Lyon for the proposal of pyridostigmine bromide as a model compound and useful discussions during the meeting. 


\section{References}

[1] A. Krasnok, I. Maksymov, A. Denisyuk, P. Belov, A. Miroshnichenko, C. Simovski, Yu. Kivshar, Physics-Uspekhi 56(6) (2013).

[2] H. Fischer, O. Martin, Opt. Express 16(12) (2008) 9144-9154.

[3] S. Kharintsev, A. Alekseev, V. Vasilchenko, A. Kharitonov, M. Salakhov, Opt. Mat. Express 5(10) (2015) 2225-2230.

[4] C. D’Andrea, J. Bochterle, A. Toma, C. Huck, F. Neubrech, E. Messina, B. Fazio, O. M. Maragò, E. Di Fabrizio, M. L. de La Chapelle, P. G. Gucciardi, A. Pucci, ACS Nano 7(4 ) (2013) 3522-3531.

[5] M. Chapelle, A. Pucci (Eds.) Nanoantenna. Surface Enhanced Spectroscopies for Biotechnological Applications, vol. 1, CRC Taylor and Francis Group, 2013.

[6] S. Schlücker, Angew. Chem. Int. Edit. 53 (2014) 4756 - 4795.

[7] K. C. Bantz, A. F. Meyer, N. J. Wittenberg, H. Im, O. Kurtulus, S. H. Lee, N. C. Lindquist, S.-H. Oh, C. L. Haynes, Phys. Chem. Chem. Phys. 13 (2011) 11551-11567.

[8] G. Fogarasi, P. Pulay, in: J.R. Durig (Ed.), Vibrational Spectra and Structure, Vol. 14, Chap. 3, Elesevier, Amsterdam, 1985, pp. 125-219.

[9] J. Bukowska, P. Piotrowski, in: M. Baranska (Ed.), Optical Spectroscopy and Computational Methods in Biology and Medicine, Vol. 14, Chap. 3, Springer, Dordrecht, Heidelberg, New York, London, 2014, pp. 29-59.

[10] D. Cialla, A. März, R. Böhme, F. Theil, K. Weber, M. Schmitt, J. Popp, Anal Bioanal Chem 403 (2012) 27-54.

[11] E. Dumont, C. Bleye, P.-Y. Sacré , L. Netchacovitch , P. Hubert, E. Ziemons, Bioanalysis 8(10) (2016) 1077-1103.

[12] M. Osawa, in: Handbook of Vibrational Spectroscopy, John Wiley \& Sons Ltd., 2006, pp. 785799.

[13] P. R. Griffiths, R Soc. Chem., 44 (2013) 95-122.

[14] L.-X. Wang, X.-E. Jiang, Chinese J of Anal Chem. 40(7) (2012) 975-982.

[15] L. V. Brown, K. Zhao, N. King, H. Sobhani, P. Nordlander, N. J. Halas, J. Am. Chem. Soc. 135 (2013) 3688-3695.

[16] A. Otto, M. Futamata, in: K. Kneipp, M. Moskovits, H. Kneipp (Eds.), Surface-Enhanced Raman Scattering - Physics and Applications, Topics Appl. Phys. Vol.103, Springer-Verlag Berlin Heidelberg, 2006, pp.147-182.

[17] P. G. Etchegoin, E. C. Le Ru, in: S. Schlucker (Ed.),Surface Enhanced Raman Spectroscopy: Analytical, Biophysical and Life Science Applications, Wiley-VCH Verlag, 2011, pp. 1-37.

[18] A. Shiohara, Y. Wang, L. M. Liz-Marzán, J. Photochem. Photobiol. C: Photochem. Rev. 21 (2014) 2-25.

[19] N. Valley, N. Greeneltch, R. P. Van Duyne, G. C. Schatz, J. Phys. Chem. Lett. 4 (2013) 2599-2604.

[20] L. Xia, M. Chen, X. Zhao, Z. Zhang, J. Xia, H. Xu, M. Sun, J. Raman Spectrosc. 45(7) (2014) 533-540.

[21] S. Morton, L. Jensen, J. Am. Chem. Soc. 131 (11) (2009) 4090-4098.

[22] O. Fesenko et al., Nanoscale Res. Lett. 10 (2015) 163.

[23] L. Dolgov et al., Nanoscale Res. Lett., 11(1) (2016) 197.

[24] P.K. Roy, Y.F. Huang, S. Chattopadhyay, J. Biomed. Opt. 19(1) (2014) 011002.

[25] J. Lee, B. Hua, S. Park, M. Ha, Y. Lee, Z. Fan and H. Ko, Nanoscale 6(1) (2014) 616-623.

[26] J. M. Sylvia et al., Anal. Chem. 72(23) (2000) 5834-5840.

[27] A. Hakonen, P. Andersson, S. M. Stenbæk, T. Rindzevicius, M. Käll Anal. Chim. Acta 893

(2015) 1-13.

[28] A. Hakonen, T. Rindzevicius, M. S. Schmidt, P. O. Andersson, L. Juhlin, M. Svedendahl, A.

Boisen, M. Käll, Nanoscale 8 (2016) 1305-1308.

[29] R.K. Lauridsen et al., Sens. Bio-Sens. Res. 5 (2015) 84-89.

[30] K. Tuovinen, E. Kaliste-Korhonen, F. M. Raushel, O. Hanninen, Toxicology 134 (1999) 169-178. 
[31] E. X. Albuquerque, E. F. R. Pereira, Y. Aracava, W. P. Fawcett, M. Oliveira, W. R. Randall, T. A. Hamilton, R. K. Kan, J. A. Romano, Jr. Adler, M. Adler, PNAS 103(35) (2006) 13220-13225.

[32] J. Smythies, B. Golomb, J. R. Soc. Med. 97 (2004) 32.

[33] E. Dolgin, Nat. Med. 19(10) (2013) 1194-1195.

[34] http://www.chemicalbook.com/SpectrumEN_114-80-7_Raman.htm

[35] W. Stöber, A. Fink, E. Bohn, J. Colloid. Interf. Sci. 26(1) (1968) 62-69.

[36] T. Pham et al., Langmuir 18 (2002) 4915-4920.

[37] S. Pikker et al., Nanoscale Res. Lett. 9 (2014) 143.

[38] V. R . Estrela-Llopis et al., Patent UA No 80781. C30B 7/14; 7/04; 29/64 Bull. №17, 25.10.2007.

[39] V. R . Estrela-Llopis et al., in: V. M. Starov (Ed.), Nanoscience Colloidal and Interfacial Aspects, Chap. 12, CRC Press, 2010, pp. 307-368.

[40] P. Klaboe, J. Am. Chem. Soc. 89(15) (1967) 3667-3676.

[41] Q. Y. Tan, N. N. Hu, G. D. Liu, H. F. Yin, L. Zhang, H. Wang, L. Y. Lu, J. Q. Zhang, Arch. Pharm. Res. 35(3) (2012) 499-508.

[42] T. Borodinova et al., J. Nano- and Electronic Phys. (rus) 4(2) (2012) 02039.

[43] S. J. Oldenburg, S. L. Westcott, R. D. Averitt, N. J. Halas, J. Chem. Phys. 111 (1999) 4729. 


\section{Table caption}

Table 1. Correlation of pyridostigmine bromide Raman bands with vibrations of its molecular groups.

\section{Figure captions}

Fig. 1. Chemical formulas of pyridostigmine bromide (a) and sarin (b).

Fig. 2. Optical microscopic image of pyridostigmine bromide droplet dried on the glass surface.

Fig. 3. Spectra from the pyridostigmine bromide film deposited on the thin gold films based on the glass and measured at different powers of incident laser light: 1) $1 \%$, 2) $50 \%$, 3) $100 \%$. Full laser power is $50 \mathrm{~mW}, \lambda_{\text {exc }}=633 \mathrm{~nm}$.

Fig. 4. Spectra of the infrared light absorption for the samples: (1) pyridostigmine bromide deposited on continuous gold film; (2) pyridostigmine bromide deposited on the $\mathrm{SiO}_{2}$-Au nanoparticles; (3) dried dispersion of $\mathrm{SiO}_{2}$-Au nanoparticles.

Fig. 5. Experimental optical microscope image of dark field light scattering from the facets of the gold microcrystals (a). Calculated distribution of light induced electric field for the gold prism with the 1.5 $\mu \mathrm{m}$ edge under normally incident light $\left(\lambda_{\mathrm{exc}}=633 \mathrm{~nm}\right)(\mathrm{b})$.

Fig. 6. Raman spectra from the pyridostigmine droplet dried on the gold microprisms (1) in comparison with referent spectrum from the grain of pyridostigmine bromide (2). Depicted intensity of spectrum (2) is 50 times higher than real one for the more convenient comparison of (1) and (2). Fluorescent background is subtracted.

Fig. 7. Raman spectra from the pyridostigmine droplet dried on the $\mathrm{SiO}_{2}-\mathrm{Au}$ nanoparticles (1) in comparison with referent spectrum from the grain of pyridostigmine bromide (2). Depicted intensity of spectrum (2) is $10^{3}$ times higher than real one for the more convenient comparison of (1) and (2). Fluorescent background is subtracted.

Fig. 8. Scanning electron microscopy of $\mathrm{SiO}_{2}-\mathrm{Au}$ nanoparticles. 